Artigo/Article

\title{
Celikates e os limites de uma teoria da crítica sem objeto
}

\section{Celikates and the limits of a theory of critique without object}

\section{Celikates y los límites de una teoría de la crítica sin objeto}

(D) Luiz Philipe de Caux ${ }^{1}$

\begin{abstract}
Resumo: Analisa-se criticamente a proposta de Robin Celikates de formular uma teoria da crítica que pense a sua relação paternalista, indulgente ou emancipatória para com os agentes sociais ordinários (isto é, os não teóricos ou não cientistas). Argumenta-se que o autor, contado como um dos pertencentes a uma "nova geração" frankfurtiana, formula um modelo de crítica afastado da crítica de objetos concretos e que isso tem consequências negativas para a sua formulação. Sob o pressuposto errôneo de que isso ofenderia a autonomia e as capacidades cognitivas dos agentes, Celikates veda à teoria crítica a constatação de processos sociais que ocorrem às suas costas, o que termina por tornar a própria atividade crítica ou desnecessária ou incapaz de atender os seus objetivos.
\end{abstract}

Palavras-chave: Teoria crítica da sociedade. Escola de Frankfurt. Positivismo. Paternalismo. Autorreflexividade.

Abstract: The article reviews critically Robin Celikates' proposal to formulate a theory of critique that thinks its paternalist, indulgent or emancipatory relationship to ordinary social agents (i.e, non-theorists or non-scientists). It argues that the author, counted as belonging to a frankfurtian "new generation", formulates a model of critique apart from the criticism of concrete objects and that this brings him negative consequences. Under the erroneous assumption that this would offend the agents' autonomy and cognitive abilities, Celikates interdicts to critical theory the verification of social processes that occur "behind their back", what ends up making the critical activity itself either unnecessary or incapable of achive its objectives.

Keywords: Critical theory of society. Frankfurt School. Positivism. Paternalism. Autorreflexivity.

Resumen: En este texto se analiza críticamente la propuesta de Robin Celikates de una teoría de la crítica que reflexione sobre su relación paternalista, indulgente o emancipadora con los agentes sociales ordinarios (es decir, los no teóricos o los no científicos). Se argumenta que el autor, considerado como haciendo parte de una "nueva generación" de Fráncfort, formula un modelo de crítica distante de la crítica de objetos concretos y que esto tiene consecuencias negativas para su formulación. Bajo

\footnotetext{
${ }^{1}$ Universidade Federal do Rio Grande do Norte (UFRN, Natal, RN, Brasil). autor.dados_biográficos
}

Civitas, Porto Alegre, v. 19, n. 3, p.692-707, set.-dez. 2019

Este artigo está licenciado sob forma de uma licença Creative Commons Atribuição 4.0 Internacional, que permite uso irrestrito, distribuição e reprodução em qualquer meio, desde que a publicação original seja corretamente citada. https://creativecommons.org/licenses/by/4.0/deed.pt_BR 
el supuesto erróneo de que esto ofendería la autonomía y las capacidades cognitivas de los agentes, Celikates veta a teoría crítica el análisis de los procesos sociales que ocurren detrás de ellos, lo que hace que la actividad en si sea o innecesaria o incapaz de cumplir sus objetivos.

Palabras-clave: Teoría crítica de la sociedad. Escuela de Fráncfort. Positivismo Paternalismo Auto-reflexividad.

\section{Introdução}

A questão metateórica e metacrítica sobre a determinação da crítica - isto é, sobre suas condições de possibilidade, seus critérios, seus portadores, seu método, seus objetivos e sua repercussão prática - marca a constituição da teoria crítica frankfurtiana, da velha e da nova, desde seus inícios e, para o bem ou para o mal, se perenizou como um de seus assuntos prediletos, revisitados à exaustão. Desde Horkheimer (1988), a necessidade de bem compreender a sua própria localização e seu papel na divisão do trabalho da sociedade capitalista força a teoria crítica a conceituar e a determinar a si própria de modo a não se confundir com a teoria que opera como força produtiva e contribui para a reprodução material e simbólica e, assim, para a continuidade da dominação. A autorreflexividade é, portanto, constituinte da teoria crítica. Nesse seu traço distintivo, todavia, está inscrito um risco: o de sua degeneração em uma vazia autorreferencialidade; e tanto mais na medida em que esta seja uma característica típica de tradições que se institucionalizam e passam a narrar a si mesmas. ${ }^{1} \mathrm{O}$ risco de seu esvaziamento é o risco do esquecimento daquilo em vista do que a crítica é levada a cabo. Se deixar de se voltar ao objeto e passar a se concentrar exclusivamente em si mesma, a teoria crítica transforma-se em uma teoria tradicional da crítica: seus critérios de criticidade não podem mais ser aplicados a si mesma. Uma falsa radicalização da autorreflexão se frustra e obtém o resultado contrário.

Muitos intérpretes notam que a teoria crítica frankfurtiana institucional terminou se aferrando, desde a proposição do paradigma reconstrutivo por Habermas, ao problema da fundamentação ou da justificação do critério da crítica (ver, por exemplo, Fleck, 2017; Freyenhagen, 2017; Vogelmann, 2017). Nesse gesto, a crítica a objetos determinados parece sair cada vez mais do centro dos interesses. Embora Habermas seja certamente a influência remota para o redirecionamento da atenção da tradição institucional ao problema -

\footnotetext{
${ }^{1}$ Conforme a crítica irônica de Heinz Steinert (2007, p. 152) sobre o "romance de família" frankfurtiano.
} 
lembre-se da objeção dirigida à velha teoria crítica: "padeceu desde o início dessa dificuldade de prestar contas de seus próprios fundamentos normativos" (Habermas, 1987, p. 500) -, o esquecimento da crítica de objetos não pode ser tributado a ele. Nos que lhe sucederam e reivindicaram o lugar de continuadores da nova teoria crítica, todavia, esse progressivo esquecimento é notável. Em Honneth, a crítica da sociedade, tenha ela êxito ou não, ainda é razoavelmente presente, mas a preocupação com a reconstrução de estruturas normativas ou com a recuperação atualizada de conceitos filosóficos tidos sem mais por conceitos críticos, para não falar da dedicação à determinação do que quer dizer fazer crítica, já não é mais apenas uma preocupação secundária.

Esse "giro para dentro de si" termina de se completar na nova geração da teoria crítica (Nobre, 2012), aquela que vem sendo chamada de "quarta geração". Nathalie Bressiani (2016) elabora as semelhanças de temas e a proveniência comum dos trabalhos recentes de Rahel Jaeggi (2005; 2009; 2009b), Robin Celikates (2006; 2009; 2012; 2014; 2015), e Martin Saar (2005; 2009a; 2009b), apontados como autores dessa geração: os três partem de um diagnóstico semelhante e parecem propor, se não uma mesma saída, uma saída do mesmo gênero:

A tese [habermasiana] da colonização do mundo da vida não é adequada, e uma teoria crítica da sociedade deve ser capaz de compreender e criticar as relações de poder que se reproduzem no interior das interações sociais. Esse projeto, já defendido por Honneth em Critica do poder, constitui o ponto de partida do trabalho desses autores, cuja principal particularidade consiste na defesa de que sua realização exige que o próprio significado da crítica social seja colocado novamente em questão. Passo com o qual eles rompem não só com Habermas, como também com Honneth (Bressiani, 2016, p. 232, grifo nosso).

Se há algo que de fato parece dar unidade a uma "nova geração" de trabalhos filosóficos da lavra de autores que fazem ou fizeram parte do Instituto de Pesquisa Social no período mais recente sob a direção de Axel Honneth, quer a reconheçamos como uma "quarta geração da teoria crítica" ou não, é notavelmente, como nota Bressiani (2016), a tomada da própria crítica como objeto de elaboração teórica. Em um giro ulterior, que completa o declínio da autorreflexão em autorreferencialidade, a nova teoria crítica não se preocupa mais apenas com os critérios normativos de uma crítica de objetos que terá lugar em um segundo momento, mas passa, admitidamente, a fazer teoria da crítica. Neste curto artigo, gostaria de examinar a teoria da crítica proposta por Robin Celikates, um dos autores que comporiam a geração pós-honnethiana 
da tradição institucional de Frankfurt, verificando a compatibilidade de sua proposta com aquilo a que ela se propõe a contribuir, isto é, com a velha ideia, que remonta a Marx, de uma teoria crítica da sociedade.

\section{A crítica e o seu destinatário}

Prefaciando o livro Crítica como práxis social, de Celikates (2009), Axel Honneth (2009, p.9) ${ }^{2}$ constata igualmente aquele estado da discussão hegemônica:

A discussão sobre as condições de possibilidade da crítica da sociedade se concentrou nas últimas décadas em grande parte na questão sobre seus critérios normativos; como se isto formasse a única coisa que hoje é controversa nas intenções de uma crítica das relações sociais, o problema de como justificar teoricamente as respectivas normas e critérios de valor subjacentes esteve no primeiro plano de quase todos os debates.

O problema que mobiliza Celikates nesse livro e em uma série de artigos, todavia, não seria esse. "A pergunta sobre de que ponto de vista a crítica acontece e em que relação ela está para com seus destinatários não é, no entanto, de modo algum idêntica à questão sobre seus fundamentos normativos" (Celikates, 2009, p. 29). O notório é que, dentre os possíveis assuntos controversos atuais da teoria crítica mencionados em abstrato por Honneth (2009), justamente um tema de "teoria da crítica" (expressão de que Celikates se vale com frequência para se referir a seu próprio trabalho) ${ }^{3}$ ocupa o interesse do autor: a questão da relação do teórico com os destinatários da crítica. Nas palavras de Celikates (2009, p. 37), o problema que o provoca é o de "que papéis desempenham as capacidades reflexivas dos atores e as práticas sociais da crítica para as formas de teoria social que designam a si próprias como críticas" e o seu objetivo é estabelecer as características de uma teoria crítica da sociedade "como uma prática social que não pressupõe uma posição epistemicamente privilegiada e não procede pela ruptura, mas pela conexão com as práticas sociais da autocompreensão e da crítica" (Celikates, 2009, p. 37). Para o autor, no que é corroborado por Honneth (2009) em seu prefácio, tal problema se afastaria do quadro monótono das discussões contemporâneas sobre a normatividade da crítica e recuperaria um problema que seria típico

\footnotetext{
${ }^{2}$ Salvo indicação em contrário, todas as traduções são de minha responsabilidade.

${ }^{3}$ Por exemplo, já no título de Celikates (2006) que exprime a direção geral de seu projeto: De uma teoria social crítica a uma teoria social da crítica (From critical social theory to a social theory of critique).
} 
da primeira geração institucional frankfurtiana, mais especificamente do texto de Horkheimer de 1937, o problema de "como o saber do teórico crítico se comporta para com os juízos pré-científicos dos integrantes ordinários da sociedade" (Honneth, 2009, p. 9; Celikates, 2009, p.29). Tenha sido ou não esse um assunto dos teóricos integrados ao redor da Revista de Pesquisa Social, e ainda que seja preciso fazer justiça ao fato de que a proposição de Celikates de um modelo de crítica ao fim do livro busca escapar da sua forma normativa ou normativista hoje hegemônica, o fato é que o modo como aborda o problema corre em paralelo ao modo como o problema do critério da crítica é tratado contemporaneamente. Trata-se ainda do lugar da crítica: não da determinação de lugar das normas que instruem a crítica, mas do lugar da crítica em relação a seus destinatários. Trata-se, para Celikates (2009), de superar duas concepções antagônicas acerca da posição do teórico crítico em relação àqueles que seriam os destinatários da crítica, o "modelo da ruptura" e o "modelo da simetria" epistemológica. Esses modelos terminam equacionados, respectivamente, aos tipos de crítica externa e interna (tipos que dizem respeito à discussão sobre o critério normativo da crítica). Celikates (2009, p. 187) entende que a crítica imanente deve ser entendida como uma forma de crítica que pretende superar a alternativa entre a crítica externa e a interna. Ora, é exatamente este o modo como pretende determinar sua concepção da "crítica como prática social", como um modelo que supere o modelo da quebra (crítica externa) e o modelo da simetria (crítica interna). Embora não se valha explicitamente da expressão, o objetivo de Celikates é explicitar o tipo de relação com os seus destinatários que caracteriza a crítica imanente.

\section{Entre o "modelo da quebra" e o "modelo da simetria"?}

A ideia de que a crítica é ela mesma uma prática social de mesmo nível que os seus objetos e destinatários - e não uma atividade teórica apartada e inconsciente de sua determinação funcional e de suas implicações sociais - constitui uma espécie de truísmo da teoria crítica. Celikates quer apresentar a teoria crítica frankfurtiana, com seu caráter reflexivo, como modelo que, diferentemente de outros dois modelos paradigmaticamente apresentados, estabelece uma relação emancipatória com os destinatários da crítica, ao nem pressupor de antemão que ser membro da sociedade é ser constitutivamente ignorante de suas regras de funcionamento, nem que a sociedade é imediatamente idêntica ao modo como os indivíduos a tomam. Nos dois casos, uma mudança social radical seria algo impossível: no primeiro, porque a ilusão dos indivíduos sobre as suas próprias determinações sociais seria funcionalmente necessária à estabilização e autoconservação do objeto 
de ordem superior "sociedade", de modo que uma tomada de consciência individual universal estaria transcendentalmente vedada ou implicaria na própria dissolução da sociedade; no segundo, porque não haveria nada a bloquear a possibilidade de uma autocompreensão individual adequada e, portanto, nada sobre o que fosse necessário tomar consciência a fim de operar uma mudança radical. A crítica social precisaria representar seus destinatários como, ao menos em tese, capazes de uma tomada de consciência.

Toda práxis emancipatória - e, assim, também uma teoria crítica que tem a emancipação por objetivo - precisa partir da igualdade, por princípio, das capacidades (por exemplo, de enfrentamento reflexivo das condições sociais sob as quais se vive e da participação em práticas sociais da crítica), e esse princípio é incompatível com a representação pedagógica de uma ruptura entre saber e compreensão de um lado e ignorância e incapacidade do outro, mesmo quando essa representação é totalmente compatível com o diagnóstico de uma distribuição desigual das possibilidades de realização dessas capacidades (Celikates, 2014, p. 144-145).

O "modelo da ruptura" é paradigmaticamente representado por Durkheim, mas Celikates (2009) estende-se mais longamente sobre a obra de Pierre Bourdieu. Celikates (2009, p. 72) rejeita esse paradigma como cientificista e objetivista: o cientista social se representaria como único que tem acesso à verdade objetiva sobre a sociedade, verdade sobre a qual os agentes ordinários não poderiam saber. No entanto, Celikates (2009) interpreta o postulado, advindo de Durkheim, de que pelo método é possível a qualquer indivíduo se pôr em condições de acessar um objeto essencialmente distinto das autocompreensões dos indivíduos, a saber, o fato social, como a representação de que há uma diferença entre as capacidades epistêmicas do cientista e do agente ordinário. Para Celikates (2009), seguindo Harold Garfinkel, o "modelo da ruptura" trataria os agentes ordinários como "idiotas desprovidos de juízo". 4

A rejeição abstrata do "modelo da ruptura", ao menos como justificada por Celikates, se baseia em um erro categorial. Se as Ciências Sociais descobrem muitas vezes - e, poder-se-ia dizer, alcançam seu objetivo quando descobrem - casos em que "o que os atores estão fazendo (objetivamente) não coincide com o que eles pensam (subjetivamente) estar fazendo" (Celikates, 2012, p.32), isso não contém qualquer juízo sobre as capacidades cognitivas dos agentes, mas antes aponta para a existência de dois objetos distintos que não

\footnotetext{
${ }^{4}$ Acato a tradução de Fernando Costa Mattos para a expressão de Garfinkel utilizada por Celikates, judgmental dopes (Celikates, 2012, p.30).
} 
se relacionam como critério de verdade um do outro: o fato social (objetivo), e a autocompreensão do agente (subjetiva, mas verdadeira, na medida em que, enquanto intenção, tem em si o critério de verdade de si mesma). $\mathrm{O}$ próprio Bourdieu (1997, p. 229) fala de uma "dupla verdade", por certo portadora de uma contradição, mas ainda assim uma "dupla verdade", por exemplo, em sua análise do fato social da troca de dádivas entre os Cabila: do ponto de vista dos agentes ou fenomenológico, é verdade que se trata de uma dádiva, caracterizada pela gratuidade, pela intenção generosa e que se subtrai ao cálculo de equivalentes; do ponto de vista do observador provido de um certo método, a saber, o estrutural, a troca de dons é uma forma de circulação econômica na qual a equivalência se produz de maneira não intencional. É errôneo caracterizar os agentes da dádiva como incapazes de compreender sua própria ação. O que eles não dispõem é da informação das consequências não intencionadas de sua ação, informação da qual, em todo caso, eles podem vir a tomar consciência (implicando isso ou não em consequências práticas). A conclusão errônea de Celikates é a de que um modelo de ciência social que busca regularidades sociais que tem lugar quer os indivíduos tenham delas consciência ou não implica na subestimação das capacidades cognitivas dos indivíduos para eventualmente lidar reflexivamente com a informação sobre essa "dupla verdade" (Bourdieu, 1997, p. 229), sobre sua condição social.

Celikates (2009), todavia, parece tratar a questão como um erro moral, como a representação, por parte do cientista social, das pessoas em geral como menos capazes. Essa representação contribuiria, segundo Celikates (2009, p. 161-162), para a manutenção das pessoas em estado de menoridade: ela seria autoritária, paternalista e mesmo esnobe. $\mathrm{O}$ remédio prescrito contra tal risco soa como uma declaração de direitos: "Devem ser asseguradas (granted) a todos os humanos as mesmas capacidades elementares dos cientistas sociais quanto se trata de questionar ideologias e representações sociais", diz Ėve Chiapello (2003, p. 157), em uma passagem citada por Celikates em ao menos quatro textos.

Entretanto, o "modelo da simetria", cujos fundamentos são bem caracterizados pelo imperativo de Chiapello (2003), também não satisfaz, já segundo Celikates, as condições para uma relação crítica da teoria com seus destinatários. Poder-se-ia dizer que se o "modelo da ruptura" peca por não ser imanente a seus destinatários, o "modelo da simetria" peca por não ser crítico. Modelos etnometodológicos, como o de Garfinkel, ou a sociologia da crítica e da justificação de Luc Boltanski (1991), representam paradigmaticamente o "modelo da simetria", para o qual a posição do cientista social não contém qualquer vantagem epistêmica em relação aos agentes ordinários, que já 
possuem capacidades reflexivas sobre suas próprias condições. A crítica não seria privilégio de uma teoria que se representaria como assumindo uma posição de externalidade ao seu destinatário, mas já seria realizada cotidianamente pelos agentes ordinários e sem qualquer diferença qualitativa em relação ao que faz teórico social.

Reflexividade e crítica - mais precisamente: a atitude reflexiva e a atitude crítica - são dimensões imanentes e constitutivas da práxis cotidiana e não apenas resultado de uma quebra com a suposta ingenuidade da atitude do mundo da vida e do "pensar e agir como de costume" (Celikates, 2009, p. 164).

Para Celikates (2012, p. 37), essa é uma afirmação verdadeira, mas não deve levar o teórico a perder de vista "a possibilidade de que certos contextos sociais sejam eficazmente blindados contra a pressão da justificação, e de que certos discursos hegemônicos de justificação suprimam recursos alternativos de argumentação", reduzindo, assim "as possibilidades de crítica disponíveis em uma sociedade".

\section{O modelo de Celikates}

Dessa objeção, Celikates (2012, p.40) extrai seu modelo de uma teoria crítica que superaria os déficits dos dois modelos abordados:

A tarefa crítica e emancipatória da teoria social está, portanto, em identificar, analisar e criticar, no contexto de um discurso envolvendo os afetados, as condições sociais que impedem ou bloqueiam a formação ou o exercício de suas capacidades reflexivas. Desse ponto de vista, a teoria social crítica é uma reflexão sobre as condições (sociais) de possibilidade da crítica e, nesse sentido, uma forma de metacrítica.

O modelo ideal de Celikates da "crítica como prática social" é um modelo metateórico e metacrítico. Como Celikates considera que a crítica seria autoritária ou paternalista se pretendesse dizer pelos indivíduos ou no lugar dos indivíduos aquilo que de algum modo está mal ou errado em sua condição, o objeto da crítica deve ser aquilo que o "modelo da simetria" não conseguiria abarcar, ou seja, os obstáculos sociais à reflexividade dos agentes que os impedem, eles mesmos, de criticar de modo independente sua própria situação. Na expressão de Celikates (2009, p. 168), os objetos da crítica não podem ser "situações 'problemáticas' (por exemplo, injustas ou alienadas) de primeira ordem" (o que seria autoritário), mas apenas “"patologia[s]' de 
segunda ordem, que se manifesta[m] em um déficit estrutural de reflexividade por parte dos atores". O objeto da crítica é aquilo que impede que os próprios agentes eventualmente exerçam a crítica. Segundo Celikates,

Para diagnosticá-las - as patologias de segunda ordem -, não se carece necessariamente já de compromissos substanciais sobre quais problemas de primeira ordem são merecedores de crítica. "Patologias" de segunda ordem são compreendidas de início de modo formal - e ainda não de modo substancial - como déficits estruturais de reflexividade [...] (Celikates, 2009, p. 169).

Dessa tarefa mínima, que não implicaria em compromissos substanciais sobre "patologias sociais", Celikates passa à determinação de como executála. Para o autor, os modelos da reconstrução racional habermasiana e da reconstrução normativa honnethiana não são adequados.

Ambas as abordagens, apesar da reconexão dialógica e das reservas falibilistas, procedem de modo essencialmente monológico, uma vez que, por princípio, uma estrutura constitutiva precisa sempre ser mostrada independente dos atores submetidos a essa estrutura e da sua autocompreensão (Celikates, 2009, p. 191).

Acertadamente, Celikates esboça um passo para fora da compreensão reconstrutiva contemporaneamente hegemônica. Tais modelos, que primeiro explicitam e justificam as normas que instruem, em um segundo momento, a crítica, não satisfazem as condições de imanência ao lugar dos destinatários. Eles se afastam epistemicamente de seus destinatários para, em um momento seguinte, proporem de fora uma reconexão. No entanto, Celikates opta por nomear seu modelo de "crítica reconstrutiva".

Para Celikates, haveria ainda outra forma de reconstrução, representada pelo modelo de Habermas (1973) em Conhecimento e interesse. Ali, Habermas (1973), sustenta que a teoria crítica deve tomar de empréstimo da psicanálise seu modo autorreflexivo de proceder, sempre extraindo de formações concretas e atuais o critério de sua superação crítica. Ora, esse é justamente o sentido de autorreflexão que Habermas (1973, p. 411) no posfácio do livro, chama de autocrítica, e não o sentido distinto que viria a ser assumido para a formulação da reconstrução. É estranho, portanto, que Celikates se filie a ele $e$ o nomeie também como reconstrução. ${ }^{5}$ De fato, Habermas (1973) se vale do termo

\footnotetext{
${ }_{5}^{5}$ Para Luiz Repa (2017, p. 17), Celikates tem aqui o "o mérito de modificar consideravelmente a orientação, amplamente aceita na literatura de comentário, segundo a qual Conhecimento e interesse seria tão-somente a origem apenas embrionária do método reconstrutivo. Ou seja, o
} 
"reconstrução" para designar o trabalho do psicanalista, mas em um sentido não fixado conceitualmente, como seria o caso após o posfácio do livro. $\mathrm{O}$ psicanalista "reconstrói" a "história prévia do paciente", "o esquecido a partir de seus textos defectivos", "sonhos, pensamentos espontâneos (Einfälle) e repetições" (Habermas, 1973, p. 282). Reconstrução, no sentido conceitual fixado na tradição institucional frankfurtiana, todavia, é reconstrução de estruturas normativas constitutivas. Em outras palavras, em que pese a terminologia, Celikates parece justamente retomar a noção de autorreflexão como autocrítica, abandonada por Habermas e pela "geração" que o sucedeu. Celikates (2009, p. 194), afirma ainda que sua reconstrução é "reconstrução de condições sociais historicamente concretas da justificação e da crítica" e que se trata de "lidar pragmaticamente a cada vez de um modo específico a contextos" (Celikates, 2014, p. 146).

A fim de não simplesmente se concluir que se trata, ali, de uma nova imposição de sentido para o termo "reconstrução", caberia talvez compreendê-la como uma forma de reconstrução que, comparada à de Habermas e de Honneth, apenas "desce" ainda um degrau no nível de generalidade do reconstruído. Se em Habermas temos estruturas formais e válidas independentemente do contexto e em Honneth certas estruturas gerais constitutivas de formas de vida determinadas, Celikates $(2009$, p. 191) propõe que "o objeto da reconstrução sejam 'patologias' concretas e sua gênese", a saber, as chamadas patologias de segunda ordem. Compreende-se melhor por que isso pode ser chamado de reconstrução com a distinção feita por Celikates (2009, p. 229). entre uma tarefa "metateórica" (analisar as condições da crítica dos agentes ordinários) e uma tarefa "metacrítica" (criticar essas condições "da crítica"). A cisão lógica em dois momentos, que Celikates antes recusara, dá agora um caráter reconstrutivo à crítica, ainda que a concretude do objeto faça com que os dois momentos precisem ter vez ao mesmo tempo. O que não resta claro é como é possível executar a primeira das tarefas sem dispor daqueles meios que já de antemão foram recusados em abstrato no chamado "modelo da ruptura".

\section{Crítica da teoria da crítica}

Celikates equivoca-se ao caracterizar o diagnóstico de déficits estruturais de reflexividade como não compromissado com qualquer concepção substancial. Para cumprir a tarefa dita "metateórica" de analisar as condições concretas da crítica e da justificação por agentes ordinários, é preciso pressupor

conceito de reconstrução emergiria principalmente na autocrítica de 1973, exposta no posfácio, a qual conteria a distinção entre reconstrução e crítica". Pelos motivos que seguem, essa interpretação contra-hegemônica não parece totalmente convincente. 
algo das situações sobre as quais eles deveriam refletir criticamente, mas não o fazem. A mera ausência de reflexividade não pode ser tomada em abstrato como um déficit, a não ser que a situação sobre a qual os agentes não refletem possa ser caracterizada como um bloqueio de reflexividade crítica, e ela só pode ser assim caracterizada sob as pressuposições: a) de que a situação é desfavorável aos agentes; b) de que eles ignoram algo sobre essa situação; c) de que, em razão de "a)" e "b)", eles deveriam refletir criticamente sobre ela; e d) de que há alguma espécie de força alheia que os impede de fazê-lo.

Sem os resultados de investigações que, procedendo por um distanciamento de método, descubram regularidades que têm lugar "às costas" dos agentes, não é possível afirmar nem que há algo a que as capacidades reflexivas dos agentes ordinários "deveriam" se dirigir, mas não o fazem, nem que há um bloqueio sistemático para essa reflexividade: nos dois casos, justamente a autocompreensão dos indivíduos não pode contar como fonte para instruir a "metacrítica" de Celikates. "Patologias" de segunda ordem, para permanecer apenas provisoriamente nessa terminologia medicalizante e organicista do social, proveniente de Honneth (2009), são também duas patologias, ambas as quais devem ser compreendidas não formal, mas substancialmente. Ademais, Celikates não chega a dizer quais seriam tais critérios formais para identificação de uma patologia de segunda ordem. De fato, o diagnóstico das assim chamadas patologias de segunda ordem, que designam déficits estruturais de reflexividade que impedem os agentes de tomar consciência e agir criticamente sobre a condição patológica de primeira ordem, parecem depender ainda mais do instrumental metodológico do "modelo da ruptura". Sem a possibilidade de descobrir processos, estruturas e regularidades sociais objetivas que não coincidem com a autocompreensão subjetiva dos agentes, não é possível demonstrar a presença de algo sobre o que a reflexão crítica cotidiana deveria se debruçar; justamente, não é possível diagnosticar uma situação de não autonomia.

A recusa em bloco do "modelo da ruptura" foi justificada em razão de sua externalidade em relação aos destinatários da crítica, que contribuiria para torná-los tão pouco autônomos quanto seriam ali concebidos. No entanto, nessa recusa parece residir um pouco mais do que essa preocupação. Celikates, de fato, se compromete com uma imagem do social como fracamente estruturado, acessível por completo à reflexão e, daí, à mudança. Nega em abstrato, por exemplo, que haja situações de ideologia como falsa consciência necessária: não pela controversa caracterização mentalista da ideologia, mas pela sua determinação como necessária. Celikates $(2009$, p. 220) rejeita que certas 
crenças compartilhadas possam ser de alguma forma induzidas por serem funcionalmente necessárias à reprodução de uma sociedade como um todo. A recusa de toda forma de estruturação social inconsciente aparece, de fato, na discussão ulterior de um aforismo de Wittgenstein (2009) no contexto da discussão sobre o que é seguir uma regra.

"Se esgotei as justificativas, cheguei então à rocha dura, e minha pá se entorta. Estou inclinado a dizer então: "É assim mesmo que ajo"” (Wittgenstein, 2009, p. 118, § 217). Partindo dessa afirmação das Investigações filosóficas, Celikates pretende se opor ao que entende como uma interpretação convencionalista do conceito de forma de vida de Wittgenstein (2009). Segundo essa interpretação, Wittgenstein (2009) apontaria para o fato de que a reflexividade crítica dos agentes no interior de uma forma de vida, a capacidade de dar razões para as próprias ações, não é ilimitada, mas se depara logo com um fato bruto que aparece como imotivado. Para Celikates, essa interpretação, que teria consequências conservadoras, poderia ser afastada compreendendo-se melhor o que Wittgenstein (2009) entende pela "rocha dura" que resta ao se esgotarem as justificativas da ação.

\begin{abstract}
A "rocha dura" ou o "dado" no qual, de acordo com algumas interpretações de Wittgenstein, a normatividade da prática, incluindo toda prática de crítica, deveria repousar tem ela mesma uma estrutura normativa, na medida em que representa não apenas a estrutura ou o pano de fundo de nossas práticas cotidianas de crítica e justificação, mas pode ela mesma também se tornar - ainda que não in toto - o tema de reflexão, crítica e transformação, i.e., de precisamente aquelas práticas que ela deveria enquadrar e limitar (Celikates, 2015, p.94).
\end{abstract}

Em outras palavras, a interpretação de Celikates basicamente dilui a noção de uma "rocha dura" que servisse de limite e suporte à série de razões potencialmente explicitadas pelos agentes em suas práticas. Se a rocha de Wittgenstein for fluidificável em novas camadas de razões explicitáveis, então ela, de fato, não é uma rocha. A ressalva restritiva de seu argumento ("ainda que não in toto") contradiz a afirmação que busca restringir, pois aquilo que restasse desse "não in toto" constituiria, justamente, a rocha não normativa de uma forma de vida. Mas é justamente isso que Celikates quer negar. Se voltamos ao mesmo parágrafo de Wittgenstein (2009), exatamente à oração que antecede citada por Celikates, temos um elemento para reinterpretar a passagem de um modo que não é nem convencionalista ou conservador, nem dilui o social em normas às quais se pode potencialmente oferecer razões. 
"Como posso seguir uma regra" - se esta não é uma pergunta pelas causas, então é uma pergunta para justificar minha maneira de agir de acordo com a regra. Se esgotei as justificativas, cheguei então à rocha dura, e minha pá se entorta. Estou inclinado a dizer então: "É assim mesmo que ajo" (Wittgenstein, 2009, p. 118, § 217).

"Esta não é uma pergunta pelas causas", é o que Wittgenstein (2009, p. 118, §217) diz logo antes. Trata-se de uma pergunta por razões, não por causas. A resposta é constituída por justificativas, motivos discursivos para a ação. Ainda que esta ligação não seja feita expressamente por Wittgenstein (2009), parece razoável interpretar a "rocha dura" que resiste quando se retrocede à ponta da sequência inferencial de razões não como um elemento da ordem das razões (interpretação de Celikates), mas sim da ordem das causas. A própria expressão remete à materialidade e à objetividade desse substrato de uma forma de vida. A ontologia social com a qual Celikates se compromete, todavia, não aceita um tal substrato. Por isso, o "modelo da ruptura", que visa justamente abarcá-lo, precisa ser duplamente recusado. Assim, Celikates perde a possibilidade de cumprir as tarefas que põe, ao fim, para si mesmo.

Se "é necessário reconhecer que o que as Ciências Sociais produzem já está incluído no círculo hermenêutico da sociedade", como diz Chiapello (2003, p. 157), seguida novamente por Celikates, é preciso então efetivamente não separar da prática social nem a ciência social do "modelo da simetria", nem a do "modelo da ruptura". A diferença entre as duas está apenas no método e no objeto que se pretende apreender, não na relação estabelecida com as capacidades cognitivas dos destinatários. Celikates está correto ao afirmar que a teoria crítica não pode pressupor a priori a não autonomia dos indivíduos, mas ela tampouco pode pressupor a autonomia. Assim, ela também não pode proibir-se de antemão a constatação de que estejam vigentes processos sociais que têm lugar às costas dos indivíduos. Por isso, o modo como autores como Adorno e Horkheimer lidaram com sociólogos "positivistas" ou que se enquadrariam no que Celikates chama de "modelo da ruptura", como Durkheim, não foi pela rejeição pura e simples dos seus métodos e resultados. Ainda que concordassem com Celikates que os resultados de tais investigações sociológicas têm repercussões antiemancipatórias e contribuem para fixar uma imagem rigidificada de sociedade, aqueles autores tomaram essas investigações como portadoras de um momento de verdade que a crítica não poderia descartar. Por isso, não começaram por pensar uma nova teoria da crítica, que estabelecesse casos válidos e inválidos de crítica, mas pensaram a crítica como crítica da teoria, que faz da crítica dos resultados das ciências particulares uma crítica das relações apreendidas por esses resultados. 


\section{Referências}

BOLTASNKI, Luc; THÉVENOT, Laurent. De la justification: les économies de la grandeur. Paris: Gallimard, 1991.

BOURDIEU, Pierre. Méditations pascaliennes. Paris: Seuil, 1997.

BRESSIANI, Nathalie. Uma nova geração da teoria crítica. Discurso, São Paulo, v. 46, n. 1, p. 231-249, 2016. Disponível em: https://doi.org/10.11606/issn.2318-8863. discurso.2016.119162. Acesso em: 22 out. 2019.

CELIKATES, Robin. From critical social theory to a social theory of critique: on the critique of ideology after the pragmatic turn. Constellations, Oxford, v. 13, n. 1, p.21-40, 2006. Disponível em: https://doi.org/10.1111/j.1351-0487.2006.00438.x. Acesso em: 22 out. 2019

CELIKATES, Robin. Kritik als soziale praxis: gesellschaftliche Selbstverständigung und kritische Theorie. Frankfurt: Campus, 2009. https://doi.org/10.21898/dia. v58i70.134

CELIKATES, Robin. O não reconhecimento sistemático e a prática da crítica: Bourdieu, Boltanski e o papel da teoria crítica. Novos Estudos CEBRAP, São Paulo, n. 93, p. 29-42, 2012. Disponível em: https://doi.org/10.1590/s0101-33002012 000200004. Acesso em: 22 out. 2019.

CELIKATES, Robin. Kritik der pädagogischen Vernunft: Bourdieu, Rancière und die Idee einer kritischen Sozialwissenschaft. In: KASTNER, Jens; SONDEREGGER, Ruth (org.). Pierre Bourdieu und Jacques Rancière: Emanzipatorische Praxis denken. Viena: Turia + Kant, 2014. p. 123-146. https://doi.org/10.14361/transcript. 9783839417171.317

CELIKATES, Robin. Against manichaeism: the politics of forms of life and the possibilities of critique. Raisons Politiques, [s. l.], n. 57, p. 81-96, 2015. Disponivel em: https://doi.org/10.3917/rai.057.0081. Acesso em: 22 out. 2019.

CHIAPELLO, Ève. Reconciling the two principal meanings of the notion of ideology: the example of the concept of "spirit of capitalism". European Journal of Social Theory, London, v. 6, n. 2, p. 155-171, 2003. Disponível em: https://doi.org/ 10.1177/1368431003006002001. Acesso em: 22 out. 2019.

FLECK, Amaro. Afinal de contas, o que é a teoria crítica? Princípios: Revista de Filosofia, Natal, v. 24, n. 44, p.97-127, 2017. Disponível em: https://doi.org/ 10.21680/1983-2109.2017v24n44id12083. Acesso em: 22 out. 2019.

FREYENHAGEN, Fabian. Was ist orthodoxe Kritische Theorie? Deutsche Zeitschrift für Philosophie, [s. l.], v. 65, n. 3, p.456-469, 2017. Disponível em: https://doi. org/10.1515/dzph-2017-0031. Acesso em: 22 out 2019. 
HABERMAS, Jürgen. Erkenntnis und Interesse: mit einem neuen Nachwort. Frankfurt: Suhrkamp Verlag, 1973.

HABERMAS, Jürgen. Theorie des kommunikativen Handelns. 4. Aufl. Frankfurt: Suhrkamp Verlag, 1987.

HONNETH, Axel. Vorwort. In: CELIKATES, Robin. Kritik als soziale praxis: gesellschaftliche Selbstverständigung und kritische Theorie. Frankfurt: Campus, 2009. p. 9-13. https://doi.org/10.21898/dia.v58i70.134

HORKHEIMER, Max. Traditionelle und kritische theorie. In: HORKHEIMER, Max. Gesammelte Schriften. Frankfurt: Fischer, 1988. (Schriften 1936-1941, v. 4), p. 162-216.

JAEGGI, Rahel. Entfrendumg: die Aktualität eines sozialphilosophischen Problems. Frankfurt: Campus, 2005.

JAEGGI, Rahel. Was ist eine (gute) Instituition? In: FORST, Rainer et al. (org.). Sozialphilosophie und Kritik. Frankfurt: Suhrkamp Verlag, 2009a. p. 528-544.

JAEGGI, Rahel. Was ist Ideologiekritik. In: WESCHE, Tilo; Jaeggi, Rahel. Was ist Kritik? Frankfurt: Surhkamp Verlag, 2009b. p. 266-295.

NOBRE, Marcos. Teoria crítica: uma nova geração. Novos Estudos CEBRAP, São Paulo, n. 93, p.23-27, 2012. Disponível em: http://dx.doi.org/10.1590/S010133002012000200003. Acesso em: 22 out. 2019.

REPA, Luiz. Compreensões de reconstrução: sobre a noção de crítica reconstrutiva em Habermas e Celikates. Trans/Form/Ação, Marília, v. 40, n. 3, p. 9-28, 2017. Diponível em: http://dx.doi.org/10.1590/s0101-31732017000300002. Acesso em: 22 out. 2019.

SAAR, Martin. Kritik als Genealogie: Geschichte und Theorie des Subjekts nach Nietzsche und Foucault. Frankfurt: Campus, 2005.

SAAR, Martin. Genealogische Kritik. In: JAEGGI, Rahel; WESCHE, Tilo. Was ist Kritik? Frankfurt: Suhrkamp Verlag, 2009a. p. 247-265.

SAAR, Martin. Macht und Kritik. In: JAEGGI, Rahel et al. (org.). Sozialphilosophie und Kritik. Frankfurt: Suhrkamp Verlag, 2009b. p.567-587.

STEINERT, Heinz. Das Verhängnis der Gesellschaft und das Glück der Erkenntnis: Dialektik der Aufklärung als Forschungsprogramm. Münster: Westfälisches Dampfboot, 2007.

VOGELMANN, Frieder. Measuring, disrupting, emancipating: three pictures of critique. Constellations, Oxford, v. 24, n. 1, p. 101-112, 2017. Disponível em: https:// doi.org/10.1111/1467-8675.12254. Acesso em: 22 out. 2019. 
WITTGENSTEIN, Ludwig. Investigações filosóficas. 6. ed. Petrópolis: Vozes, 2009.

Recebido em: 23/6/2018.

Aprovado em: 13/6/2019.

Publicado em: 15/12/2019.

Autor correspondente:

Luiz Philipe de Caux

Rua Mato Grosso, 666, ap. 703-B - Bairro Barro Preto

30190-080, Belo Horizonte, MG, Brasil

LuIz PhILIPE DE CAUX <luizphilipedecaux@gmail.com>

Doutor em Filosofia pela Universidade Federal de Minas Gerais (UFMG, Belo Horizonte, MG, Brasil). Professor da Universidade Federal do Rio Grande do Norte (UFRN, Natal, RN, Brasil).

Orcid: http://orcid.org/0000-0002-2458-5563 